\title{
Off-line sampling of exhaled air for nitric oxide measurement in children: methodological aspects
}

\author{
Q. Jöbsis*, , S.L. Schellekens*, A. Kroesbergen*, W.C.J. Hop\#, J.C. de Jongste*
}

Off-line sampling of exhaled air for nitric oxide measurement in children: methodological aspects. Q. Jöbsis, S.L. Schellekens, A. Kroesbergen, W.C.J. Hop, J.C. de Jongste. C ERS Journals Ltd 2001.

ABSTRACT: Measurement of nitric oxide in exhaled air is a noninvasive method to assess airway inflammation in asthma. This study was undertaken to establish the reference range of exhaled NO in healthy school-aged children and to determine the influence of ambient NO, noseclip and breath-holding on exhaled NO, using an off-line balloon sampling method.

All children attending a primary school (age range 8-13 yrs) underwent NO measurements on two occasions with high and low ambient NO. Each time, the children performed four expiratory manoeuvres into NO-impermeable balloons, with and without $10 \mathrm{~s}$ of breath-holding and with and without wearing a noseclip. Exhalation flow and pressure were not controlled. NO was measured within $4 \mathrm{~h}$ after collection, by means of chemiluminescence. All children completed a questionnaire on respiratory and allergic disorders, and performed flow/volume spirometry.

With low ambient NO, the mean exhaled NO value of 72 healthy children with negative questionnaires and normal lung function was $5.1 \pm 0.2$ parts per billion (ppb) versus a mean of $6.8 \pm 0.3 \mathrm{ppb}$ in the remaining 49 children with positive questionnaires for asthma and allergy, and/or recent symptoms of cold $(p=0.001)$. Exhaled and ambient NO were significantly related, especially with ambient $N O>10 \mathrm{ppb}(\mathrm{r}=0.86$, $\mathrm{p}=0.0001$ versus $\mathbf{r}=\mathbf{0 . 3 4}, \mathrm{p}=\mathbf{0 . 0 0 4}$ for ambient values $<10 \mathrm{ppb}$ ). The use of a noseclip, with low ambient NO and without breath-holding, caused a small decrease in exhaled NO values $(p=0.001)$. The effect of breath-holding on exhaled NO depended on ambient NO. With ambient NO $>10 \mathrm{ppb}$, exhaled NO decreased, whereas with ambient NO $<10 \mathrm{ppb}$, exhaled NO increased after $10 \mathrm{~s}$ breath-hold.

It is concluded that off-line sampling in balloons is a simple and, hence, attractive method for exhaled nitric oxide measurements in children which differentiates between groups with and without self-reported asthma, allergy and colds, when ambient nitric oxide is $<\mathbf{1 0}$ parts per billion. Wearing a noseclip and breath-holding affected measured values and should, therefore be standardized or, preferably, avoided. Eur Respir J 2001; 17: 898-903.
* Dept of Paediatrics, Division Paediatric Respiratory Medicine, and ${ }^{\#}$ Dept of Epidemiology and Biostatistics, Erasmus University and University Hospital/Sophia Children's Hospital, Rotterdam and "Dept of Paediatrics, University Hospital Maastricht, the Netherlands.

Correspondence: J.C. de Jongste

Sophia Children's Hospital

Room Sp-2465

P.O. Box 2060

3000 CB Rotterdam

the Netherlands

Keywords: Asthma

breath-hold

children

exhaled air

nitric oxide

off-line sampling

Received: April 261999

Accepted after revision January 24 2001

This study was supported by a research grant of the Netherlands Asthma Foundation (NAF 94.14).
Nitric oxide (NO) is a reactive free radical gas produced by various cells within the respiratory tract. It plays an important role in the pathophysiology of inflammatory airway disease and can be detected in exhaled air [1-4]. There is now convincing evidence that $\mathrm{NO}$ in exhaled air $(\mathrm{eNO})$ is a noninvasive marker of airway inflammation in various airway disorders $[1,5,6]$. Recently, slow exhalation from total lung capacity with a constant flow against a resistance was recommended for measurement of eNO [6]. However, this manoeuvre is difficult to perform for many children [7], and requires the presence of an NOanalyser and equipment to measure flow with a visual feedback control. The present authors have developed a simple off-line, single breath, balloon sampling method to measure eNO. Blowing air in a balloon is feasible even for young children, and produces values similar to those of end-expiratory plateaus $[7,8]$. Offline sampling has the advantage that children may be studied at home or school, and that it can be used for large epidemiological studies, independent from the direct presence of an NO-analyser. The aim of this study was to establish a reference range of eNO sampled in balloons, of a large group of healthy school-aged children. Furthermore, the influence of ambient NO, the effect of $10 \mathrm{~s}$ of breath-holding and the use of a noseclip was examined.

\section{Patients and methods}

All pupils of a primary school $(n=129)$ participated. They were interviewed with validated questionnaires on asthma, allergy, eczema and rhinitis, translated from the core questionnaires on wheezing, rhinitis amd eczema of the International Study of Asthma and Allergies in Childhood (ISAAC) [9]. In addition they were asked about recent symptoms of cold (stuffy or running nose, sneezing, coughing, sore throat, with or without fever). Measurement of eNO was performed on two occasions in the same children. On the first occasion, the ambient NO was high 
(median 35 parts per billion (ppb), range 15-188 ppb). At that time, 91 children (mean age $10 \mathrm{yrs}$ ) had negative questionnaires on asthma, allergy and eczema (all questions answered negatively) and did not report symptoms of cold within the 3 weeks before the measurements. On the second occasion 3.5 months later, ambient $\mathrm{NO}$ was low (median $7.0 \mathrm{ppb}$, range 1.5-9.0 ppb). At that time, 8 children were absent, 72 of the 91 who initially had negative ISAAC questionnaires reported no symptoms of cold, and 49 had either positive ISAAC questionnaires or reported a recent cold. Measurements took place during several sessions at each occasion, always between 14.00 and $16.00 \mathrm{~h}$. Ambient NO was drawn and stored for later analysis before and after each session, and the mean of these two samples was taken as the ambient NO concentration at that session. All children were selfreported never-smokers, never had had any other chronic illness, and used no medication. The study was approved by the hospital ethical committee.

\section{Exhaled air sampling and nitric oxide measurements}

The children were asked to take a deep oral breath and exhale via a piece of plastic tubing into a mylar balloon with a maximum content of $1,750 \mathrm{~mL}$. These balloons were impermeable to and nonreactive with NO [10]. The plastic tube (internal diameter $3.7 \mathrm{~mm}$ and length $5 \mathrm{~cm}$ ) worked as a fixed flow restrictor, causing a positive mouth pressure during the exhalation manoeuvre. Preliminary experiments showed that with a flow of $250 \mathrm{~mL} \cdot \mathrm{min}^{-1}$, this pressure is $6 \mathrm{cmH}_{2} \mathrm{O}$. At the school, exhalation flow and mouth pressure were not monitored. Subjects filled the balloon within 3-5 s. The range of expiratory volumes which were collected was $250-1,750 \mathrm{~mL}$, the extrapolated expiratory flows thus ranged between $250-600 \mathrm{~mL} \cdot \mathrm{s}^{-1}$.

All subjects performed expiratory manoeuvres into four balloons: 1) immediate exhalation with a noseclip; 2) immediate exhalation without a noseclip; 3) exhalation after breath-holding for $10 \mathrm{~s}$ with a noseclip; 4) exhalation after breath-holding for $10 \mathrm{~s}$ without a noseclip. All measurements were performed with the children seated. The NO concentration in balloons was measured within $4 \mathrm{~h}$ after collection. Air was drawn out of the balloons at $200 \mathrm{~mL} \cdot \mathrm{min}^{-1}$ by a chemiluminescence analyser (Sievers 280, Boulder, CO, USA) with a response time of $200 \mathrm{~ms}$. The NO profile showed a rapid rise to a steady NO plateau, at which eNO was calculated. The analyser was regulary calibrated according to the manufacturer's guidelines, with two different certified NO gases (100 ppb and 9 parts per million (ppm)) and a certified NO free air mixture (HoekLoos, Barendrecht, the Netherlands).

\section{Lung function}

All subjects performed maximal expiratory flow/ volume spirometry immediatly after eNO was collected in the balloons on the first occasion. Flow/ volume curves were obtained in triplicate using a calibrated single breath electronic screening spirometer (Vicatest P2A, Mijnhardt, Zeist, the Netherlands). Results of expiratory forced vital capacity (FVC) and forced expiratory volume in one second (FEV1) were expressed as percentage of predicted values [11].

\section{Stability of exhaled nitric oxide in balloons}

Five subjects each filled one balloon with orally exhaled air and one with nasally exhaled air. These balloons were sealed and stored at room temperature. During a period of $6 \mathrm{~h}$, air was sampled for NO measurements at hourly intervals.

\section{Data analysis}

Data of NO measurements were fed into a computer at a sampling rate of $20 \mathrm{~Hz}$. Mean values during $30 \mathrm{~s}$ sampling of the plateau were calculated. Correlation between eNO and other variables were analysed in a multiple regression model. In this model, eNO was entered as the dependent variable and ambient NO, sex, age and FEV1 were entered as independent variables. Differences between healthy and "diseased" groups were evaluated with a t-test for independent samples. Differences between eNO values at high and low ambient NO within groups were tested using a paired sample t-test. The relationship between eNO and ambient NO concentrations was tested with Spearman's rank test. Data are reported as mean \pm SEM. In all statistical comparisons, a two-tailed p-value $<0.05$ was considered significant.

\section{Results}

Characteristics of the study population are given in table 1 . There were no differences in age, male/female ratio, anthropometric data and lung function between healthy and "diseased" groups at both sampling moments.

\section{Reference values}

All children performed the sampling procedures without difficulty. Values obtained in 72 healthy children, not wearing noseclips, without breath-hold, and while ambient NO was below $10 \mathrm{ppb}$, are considered as reference values and show a normal, symmetrical distribution with a mean level of $5.1 \pm 0.2 \mathrm{ppb}(95 \%$ reference interval $1.7-8.5 \mathrm{ppb})$. Exhaled NO was similar in male and female children (means $5.1 \mathrm{ppb}$ and $4.9 \mathrm{ppb}$, respectively, $\mathrm{p}=0.15$ ). There was no significant correlation between eNO and FVC or FEV1 $(p=0.56)$. A significant positive correlation was found between age and eNO; for every 10 months of increasing age eNO increased $0.3 \pm 0.1 \mathrm{ppb}(\mathrm{p}=0.013)$. Individual data and $95 \%$ reference interval are given in figure 1 . The children of the "diseased" group $(\mathrm{n}=49)$ with positive questionnaires on asthma, rhinitis, and/or eczema, and/or 
Table 1. - Patient characteristics on two occasions, with high and low ambient nitric oxide (NO)

\begin{tabular}{lcccr}
\hline \multirow{2}{*}{ Characteristic } & \multicolumn{2}{c}{ Ambient NO $<10 \mathrm{ppb}}$. & \multicolumn{2}{c}{ Ambient NO $>10 \mathrm{ppb.}$} \\
\cline { 2 - 3 } & Healthy & Diseased** & Healthy & Diseased \\
\hline Subjects $n$ & 72 & 49 & 91 & 38 \\
Sex M/F & $31 / 41$ & $28 / 21$ & $46 / 45$ & $19 / 19$ \\
Age months & $123.8 \pm 1.8$ & $123.3 \pm 2.2$ & $125 \pm 1.6$ & $120.2 \pm 2.5$ \\
Height cm & $144.3 \pm 1.2$ & $144.4 \pm 1.6$ & $38.6 \pm 1.1$ & $142.8 \pm 2.5$ \\
Weight kg & $37.8 \pm 1.0$ & $38.8 \pm 1.2$ & $98 \pm 0.9$ & $38.0 \pm 1.5$ \\
FVC \% pred & $98 \pm 1$ & $99 \pm 1$ & $99 \pm 1$ & $100 \pm 2$ \\
FEV1 \% pred & $99 \pm 1$ & $99 \pm 1$ & $99 \pm 2$ \\
\hline
\end{tabular}

Data are presented as mean \pm SD. ppb: parts per billion; M: male; F: female; FVC: forced vital capacity; FEV1: forced expiratory volume in one second. **: a positive questionnaire for asthma and allergy, and/or recent or current symptoms of cold.

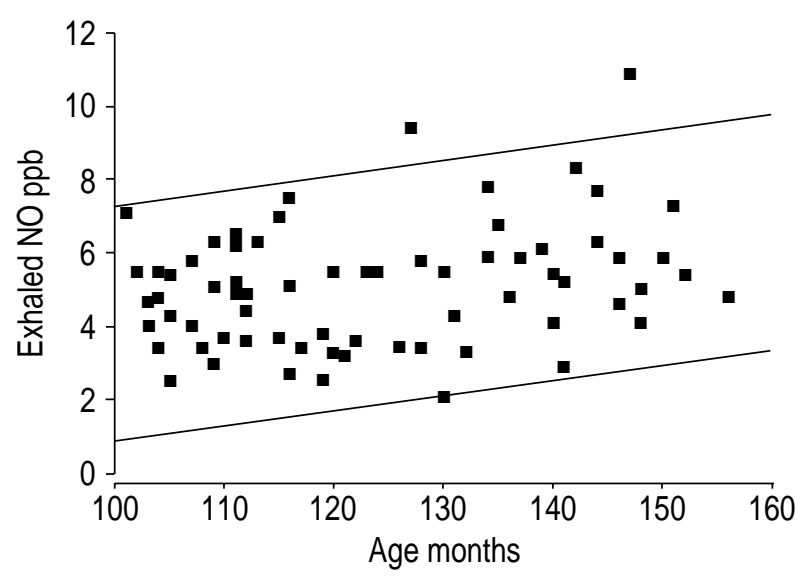

Fig. 1.-Exhaled nitric oxide (NO) of 72 healthy school children versus age. Values are from children without reported asthma, allergy or recent cold, and were measured when ambient NO was $<10$ parts per billion (ppb). All measurements were done without breath hold or noseclip. There is a small but significant increase in NO with increasing age, corresponding to $0.3 \pm 0.1 \mathrm{ppb}$ per 10 months $(r=0.3, p=0.013)$. Lines indicate the $95 \%$ reference interval.

symptoms of cold within 3 weeks before eNO measurements, with ambient $\mathrm{NO}<10 \mathrm{ppb}$, showed a significantly higher mean eNO than the corresponding healthy group $(6.8 \pm 0.3 \mathrm{ppb}, \mathrm{p}=0.001)$. The mean eNO values of the healthy and "diseased" groups of children under the different measurement conditions, with ambient $\mathrm{NO}<10 \mathrm{ppb}$, are given in table 2 .

\section{Effect of ambient nitric oxide}

High concentrations of ambient NO led to significantly higher eNO values in healthy children:
$19.2 \pm 1.6 \mathrm{ppb}$ with ambient $\mathrm{NO}>10 \mathrm{ppb}$ versus $5.1 \pm 0.2 \mathrm{ppb}$ with ambient NO $<10 \mathrm{ppb}(\mathrm{p}<0.0001)$. Exhaled NO values and ambient NO concentrations were significantly related (fig. 2). With ambient NO levels $>10 \mathrm{ppb}$ this relationship was stronger than with levels $<10 \mathrm{ppb}(\mathrm{r}=0.86, \mathrm{p}<0.0001$ versus $\mathrm{r}=0.34, \mathrm{p}=0.004$, respectively). Between 0 and $10 \mathrm{ppb}$, eNO increases with $0.2 \pm 0.2 \mathrm{ppb} \cdot \mathrm{ppb}$ increase of ambient $\mathrm{NO}^{-1}$. Wearing a noseclip had no influence on the observed relation between eNO and ambient NO.

\section{Effect of noseclip}

The noseclip significantly reduced eNO values when ambient NO was $<10 \mathrm{ppb}$. In 72 healthy children, the mean eNO value was $4.5 \pm 0.2 \mathrm{ppb}$ with, and $5.1 \pm 0.2 \mathrm{ppb}$ without noseclip $(\mathrm{p}=0.001)$. There was no significant effect of a noseclip on eNO values under all other measurement conditions: high ambient NO levels with $(\mathrm{p}=0.2)$ or without breath-holding $(\mathrm{p}=0.9)$ and low ambient NO levels with breathholding $(\mathrm{p}=0.4)$.

\section{Effect of breath-holding}

In healthy children, $10 \mathrm{~s}$ of breath-holding resulted in an increase in eNO from $5.1 \pm 0.2 \mathrm{ppb}-6.4 \pm 0.4 \mathrm{ppb}$ $(\mathrm{p}<0.0001)$ with ambient $\mathrm{NO}<10 \mathrm{ppb}$. In contrast, $10 \mathrm{~s}$ of breath-holding produced a significant reduction of eNO from $19.2 \pm 1.6 \mathrm{ppb}-9.6 \pm 0.8 \mathrm{ppb}(\mathrm{p}<0.0001)$ with ambient $\mathrm{NO}>10 \mathrm{ppb}$.

Table 2. - Nitric oxide (NO) values of schoolchildren with and without reported symptoms of asthma, allergy or colds (indicated as healthy and diseased, respectively), with and without noseclip or breath-holding, measured when ambient NO was $<10 \mathrm{ppb}$

\begin{tabular}{|c|c|c|c|c|c|}
\hline Status & $\begin{array}{l}\text { Subjects } \\
\mathrm{n}\end{array}$ & $\begin{array}{l}\mathrm{NC}- \\
\mathrm{BH}-\end{array}$ & $\begin{array}{l}\mathrm{NC}+ \\
\mathrm{BH}-\end{array}$ & $\begin{array}{l}\mathrm{NC}+ \\
\mathrm{BH}+\end{array}$ & $\begin{array}{l}\mathrm{NC}- \\
\mathrm{BH}+\end{array}$ \\
\hline $\begin{array}{l}\text { Healthy } \\
\text { Diseased }\end{array}$ & $\begin{array}{l}72 \\
49\end{array}$ & $\begin{array}{r}5.1 \pm 0.2(2.1-10.9) \\
6.8 \pm 0.3^{*}(2.4-15.3)\end{array}$ & $\begin{array}{c}4.5 \pm 0.2 * *(1.1-9.5) \\
5.9 \pm 0.4 *(1.8-14.3)\end{array}$ & $\begin{array}{r}6.2 \pm 0.4^{* *}(2.2-20.5) \\
8.9 \pm 1.1^{*}(2.0-46.2)\end{array}$ & $\begin{array}{r}6.4 \pm 0.4^{* * *}(2.7-21.6) \\
8.3 \pm 0.9^{*}(2.3-32.1)\end{array}$ \\
\hline
\end{tabular}

Data are presented as mean \pm SD (range). NC: nose clip; BH: breath-holding; +: worn/performed; -: not worn/performed. $*: \mathrm{p}<0.001$ compared to healthy children, same measurement conditions; $* *: \mathrm{p}<0.001$ compared to healthy children without noseclip and breath-hold; ***: $\mathrm{p}<0.0001$ compared to healthy children without noseclip and breath-hold. 


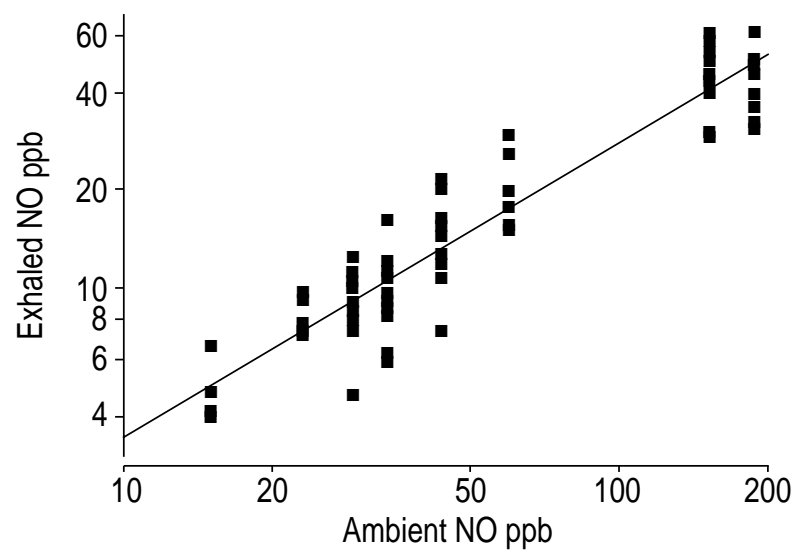

Fig. 2. - Exhaled nitric oxide (NO) versus ambient NO on days with ambient values $>10$ parts per billion (ppb) in 91 healthy children. Note that both axes are logarithmical. There is a significant correlation (Spearman rho $=0.86, \mathrm{p}=0.0001$ )

\section{Stability of exhaled nitric oxide in balloons}

The NO concentration in 5 mylar-balloons with nasal air was $36.4 \pm 1.8 \mathrm{ppb}$ and with oral air $7.5 \pm 0.9 \mathrm{ppb}$. Nasal and oral NO concentrations in the balloons were stable for at least 6 h (fig. 3).

\section{Discussion}

In this study, a reference range of eNO obtained off-line with balloon sampling in a large group of healthy school-aged children was defined. The mean eNO concentration of healthy children in the study is in agreement with eNO concentrations of healthy children from a number of previous studies [12-16]. Furthermore, it has been shown that a number of methodological factors influence eNO collected offline in balloons, including ambient NO, the use of a noseclip and breath-holding. Significant differences

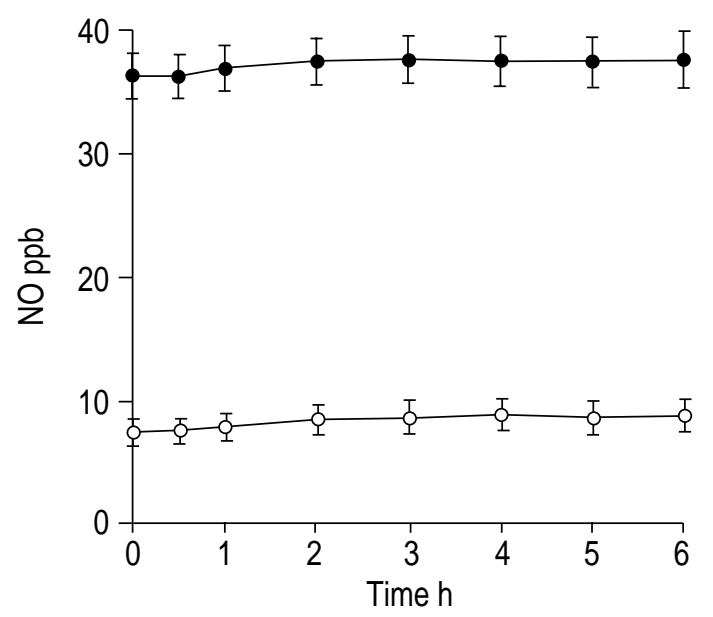

Fig. 3.-Nitric oxide concentrations (NO) in mylar-balloons, stored for $6 \mathrm{~h}$ at room temperature. 0 : mean (NO) from 5 balloons containing nasal air; $\bigcirc$ : mean (NO) from 5 balloons containing orally exhaled air. Concentrations were stable in time. ppb: parts per billion. between children with and without self-reported asthma, allergy and colds were deteted, suggesting that this method is sufficiently sensitive to detect minor degrees of airway inflammation in groups of otherwise healthy school-aged children.

There are a number of factors that should be considered when comparing the present simple off-line sampling technique with more complicated on-line sampling techniques where flow is controlled and the NO signal displayed during exhalation.

It has previously been shown that despite lack of flow standardization, off-line sampling in balloons produces eNO values that are reproducible and similar to those of end-expiratory plateaus measured on-line with constant flow [7]. It has also been shown that eNO is flow-dependent, but mainly at flows of $\leq 150 \mathrm{~mL} \cdot \mathrm{s}^{-1}$ [17-19], whereas eNO is much less flowdependent at higher flows. The children in the present study blew relatively high flows of $\geqslant 250 \mathrm{~mL} \cdot \mathrm{s}^{-1}$. This could explain why eNO in balloons is reproducible despite a lack of flow standardization [7].

In a previous study, an excellent within-subject short-term repeatability of eNO was shown, with an intraclass correlation coefficient (ri) of 0.91 , using the same technique without wearing a noseclip [7]. Small alterations of this original sampling technique, like the use of a noseclip or $10 \mathrm{~s}$ breath-holding, could potentially influence the repeatability. It has previously been shown that short-term repeatibility in clinicallly stable allergic asthmatic children was also excellent when a noseclip was used $(\mathrm{ri}=0.96)[7,8,14,21]$. This study did not specifically investigate the influence of $10 \mathrm{~s}$ breath-holding on the repeatability of eNO obtained with the off-line balloon method, and no such data are available in the literature.

Contamination with nasal NO is another potential problem with off-line sampling. An expiratory resistance is recommended to isolate the lower airway gas from gas with much higher NO concentrations produced in the nose and paranasal sinuses [6]. In the present study, balloons were filled via a plastic tube during a single oral exhalation. The tube worked as a fixed flow restrictor which causes a positive mouth pressure during the exhalation manoeuvre. It has been shown in adults that a mouth pressure of $4 \mathrm{cmH}_{2} \mathrm{O}$ is sufficient to keep the soft palate closed, thus preventing contamination with NO from upper airways [22]. Studies on mouth pressure and velum closure were performed in adults; it may well be that lower pressures close the velum in children. The lowest estimated mean exhalation flow of $250 \mathrm{~mL} \cdot \mathrm{s}^{-1}$ in this study produced a mouth pressure of $6 \mathrm{cmH}_{2} \mathrm{O}$. This should be sufficient to close the velum, and the authors are therefore confident that contamination with NO from the upper airways, despite the simple set-up without monitoring of flow or pressure during exhalation, did not occur to an important degree.

The potential effect of NO in the dead space air volume on eNO in the balloon is another point of concern. Children have a smaller dead space volume than adults which, in a similar balloon volume, will cause a smaller effect on NO values. The authors speculate that, in children, the effect of the dead space air on the eNO value will be minimal when ambient 
NO is $<10 \mathrm{ppb}$, and when subjects inhale orally before exhaling into the balloon, as was done in the present study.

Previous studies on the effect of ambient NO on eNO vary remarkably. Some authors found no influence of ambient NO on eNO values [23-27], others found important effects [28-32]. This study found a strong positive relationship between ambient $\mathrm{NO}$ concentrations and eNO in balloons. The variation of sampling techniques used in the different studies probably explains the differences. As an example, Corradi et al. [32] found no relationship between ambient NO and eNO in balloons, with ambient $\mathrm{NO}<35 \mathrm{ppb}$, but the expiration in their study in adults took $\geqslant 20 \mathrm{~s}$ compared to $3-5 \mathrm{~s}$ in the present study. This may explain the difference, as this study found that breath-hold significantly reduced the effect of high ambient NO on exhaled values. The positive relationship between ambient and eNO was more pronounced with high ambient levels, but there was also a positive correlation at ambient NO levels below $10 \mathrm{ppb}$. The magnitude of this effect, a mean rise of eNO $0.2 \mathrm{ppb}$ for each $1 \mathrm{ppb}$ rise in ambient $\mathrm{NO}$, is small compared to the differences in eNO between healthy and "diseased" children. To minimize the effect of ambient $\mathrm{NO}$ on eNO, the present authors recommend that eNO should not be measured when ambient NO is above $10 \mathrm{ppb}$. Ambient NO should be recorded, or sampled in balloons and analysed later. Alternatively, NO-free air may be inhaled before sampling, but this makes the method more complicated and formal comparisons of these approaches have not been performed.

The present study found a significant correlation between an increase in eNO concentrations and increasing age in healthy children. A possible explanation is the influence of the different dead space air volumes on eNO values in balloons. It could also be speculated that this correlation is caused by increasing nasal contamination of the eNO with age, due to development and pneumatization of the paranasal sinuses in childhood. Indeed, nasal NO increases with age, reaching levels similar to those in adults at the age of $\sim 10 \mathrm{yrs}$, and this corresponds roughly with the period of sinus development [33]. However, oral pressures were probably sufficient to close the velum and prevent contamination by nasal NO [22]. Furthermore, FRANKLIN et al. [34] recently described a positive correlation between eNO and age in a comparable group of healthy children using an online, single breath, plateau technique at a mouth pressure of $15 \mathrm{cmH}_{2} \mathrm{O}$ [34]. Other eNO studies in children have not been able to demonstrate a relationship of eNO with age $[14,15,30]$. However, a number of methodological differences of the different studies makes it difficult to compare results, for instance, differences in age, in sampling methods with eNO values obtained in different ways, and in dealing with the ambient NO.

It has been stated that using a noseclip enhances nasal contamination of eNO, although there are no data to support this $[2,10,17]$. Several investigators routinely require subjects to wear noseclips during NO measurements $[10,26,31,35]$, while others do not
$[17,21,36]$. Without a noseclip, diffusion of NO through the nares as well as into the posterior nasopharynx is possible; with a noseclip only diffusion towards the pharynx can occur, and this would increase contamination with high nasal NO levels. Using the present off-line, single breath, balloon sampling method with an expiratory resistance, it was found that a noseclip in combination with low ambient NO levels causes a small but significant decrease in exhaled NO values. A possible explanation is that a noseclip prevents a minimal nasal inspiration, thus preventing contamination of eNO with nasal NO. Although a noseclip only minimally affected eNO, the present data do not argue against the European Respiratory Society Task Force recommendation not to use noseclip during NO measurement [6].

Prior studies have shown that breath-holding increases eNO in asthmatics and in healthy subjects in a time dependent fashion [10, 17, 37, 38]. However, others have shown that when $40 \mathrm{ppm}$ is inhaled, a breath-hold of several seconds reduced NO in exhaled air to 1-3 ppm [25]. This decrease may be caused by rapid uptake of NO by haemoglobin in the lung capillaries $[17,25,39]$. This present study found that the effect of breath-holding on eNO depends on ambient NO; with high levels, breath-holding reduces NO, whereas with low levels it increases eNO. It is not likely that these results are influenced by nasal contamination during breath-holding or in the oral expiration phase, as shown earlier with an inert tracer gas [22].

It is concluded that off-line measurement of nitric oxide sampled in balloons, is a simple and feasible method of measuring exhaled nitric oxide in children. Off-line sampling has the important advantage that it offers independence from the presence of a nitric oxide analyser. Off-line balloon sampling without use of a noseclip and without breath-hold, and with ambient nitric oxide levels $<10$ parts per billion, shows differences between healthy children and those with self-reported asthma, allergy or cold, confirming that exhaled nitric oxide may be used as a surrogate marker of airway inflammation. The simplicity of this method makes it attractive for studies in larger populations, where differences between groups can be detected.

Acknowledgements. The authors are indebted to the children and teachers of the De Wilgenstam school in Rotterdam, who participated in this study.

\section{References}

1. Lundberg JON, Weitzberg E, Lundberg JM, Alving K. Nitric oxide in exhaled air. Eur Respir J 1996; 9: 2671-2680.

2. Barnes PJ, Kharitonov SA. Exhaled nitric oxide: a new lung function test. Thorax 1996; 51: 233-237.

3. Gaston B, Drazen JM, Loscalzo J, Stamler JS. The biology of nitrogen oxides in the airways. Am J Respir Crit Care Med 1994; 149: 538-551.

4. Gustafsson LE, Leone AM, Persson MG, Wiklund 
NP, Moncada S. Endogenous nitric oxide is present in the exhaled air of rabbits, guinea pigs and humans. Biochem Biophys Res Commun 1991; 181: 852-857.

5. Dinh-Xuan AT, Texereau J. Measuring exhaled nitric oxide: not only a matter of how - but also why - should we do it? Eur Respir J 1998; 12: 1005-1007.

6. Kharitonov SA, Alving K, Barnes PJ. Exhaled and nasal nitric oxide measurements: recommendations. Eur Respir J 1997; 10: 1683-1693.

7. Jöbsis Q, Schellekens SL, Kroesbergen A, Hop WCJ, de Jongste JC. Sampling of exhaled nitric oxide in children: end-expiratory plateau, balloon and tidal breathing methods compared. Eur Respir J 1999; 13: 1406-1410.

8. Paredi P, Loukides S, Ward S, et al. Exhalation flow and pressure-controlled reservoir collection of exhaled nitric oxide for remote and delayed analysis. Thorax 1998; 53: 775-779.

9. Asher MI, Keil U, Anderson HR, et al. International study of asthma and allergies in childhood (ISAAC): rationale and methods. Eur Respir J 1995; 8: 483-491.

10. Kimberly B, Nejadnik B, Giraud GD, Holden WE. Nasal contribution to exhaled nitric oxide at rest and during breathholding in humans. Am J Respir Crit Care Med 1996; 153: 829-836.

11. Zapletal A, Samanek M, Paul T. Lung function in children and adolescents. Methods, reference values. Basel, Karger Verlag, 1987; 191-197.

12. Lundberg JON, Nordvall SL, Weitzberg E, Kollberg $\mathrm{H}$, Alving K. Exhaled nitric oxide in peadiatric asthma and cystic fibrosis. Arch Dis Child 1996; 75: 323-326.

13. Balfour-Lynn IM, Laverty A, Dinwiddie R. Reduced upper airway nitric oxide in cystic fibrosis. Arch Dis Child 1996; 75: 319-322.

14. Nelson BV, Sears S, Woods J, et al. Expired nitric oxide as a marker for chidhood asthma. J Pediatr 1997; 130: 423-427.

15. Artlich A, Hagenah JU, Jonas S, Ahrens P, Gortner L. Exhaled nitric oxide in childhood asthma. Eur J Pediatr 1996; 155: 698-701.

16. Frank TL, Adisesh A, Pickering AC, et al. Relationship between exhaled nitric oxide and childhood asthma. Am J Respir Crit Care Med 1998; 158: 1032-1036.

17. Silkoff PE, McClean PA, Slutsky AS, et al. Marked flow-dependence of exhaled nitric oxide using a new technique to exclude nasal nitric oxide. Am J Respir Crit Care Med 1997; 157: 260-267.

18. Kroesbergen A, Jöbsis Q, Bel EHD, de Jongste JC. Flow-dependency of nitric oxide in exhaled air in children with asthma and cystic fibrosis. Eur Respir $J$ 1999; 14: 871-875.

19. Högman M, Strömberg S, Schedin U, Frostell C, Hedenstierna G, Gustafsson LE. Nitric oxide from the human respiratory tract efficiently quantified by standardized single breath measurements. Acta Physiol Scand 1997; 159: 345-346.

20. Jöbsis Q, de Jongste JC. Comparison of three different sampling methods of exhaled nitric oxide in children. Am J Respir Crit Care Med 1997; 155: A970.

21. Salome CM, Roberts AM, Brown NJ, Dermand J, Marks GB, Woolcock AJ. Exhaled nitric oxide measurements in a population sample of young adults. Am J Respir Crit Care Med 1999; 159: 911-916.

22. Kharitonov SA, Barnes PJ. Nasal contribution to exhaled nitric oxide during exhalation against resistance or during breath holding. Thorax 1997; 52: 540-544.

23. Piacentini GL, Bodini A, Vino L, et al. Influence of environmental concentrations of $\mathrm{NO}$ on the exhaled NO test. Am J Respir Crit Care Med 1998; 158: 1299-1301.

24. Robbins RA, Floreani AA, Von Essen SG, et al. Measurement of exhaled nitric oxide by three different techniques. Am J Respir Crit Care Med 1996; 153: 1631-1635.

25. Borland C, Cox Y, Higenbottam T. Measurement of exhaled nitric oxide in man. Thorax 1993; 48: $1160-1162$

26. Massaro F, Gaston G, Kita D, Fanta C, Stamler JS, Drazen JM. Expired nitric oxide levels during treatment of acute asthma. Am J Respir Crit Car Med 1995; 152: 800-803.

27. Kharitonov SA, Yates D, Robbins RA, LoganSinclair R, Shinebourne EA, Barnes PJ. Increased nitric oxide in exhaled air of asthmatic patients. Lancet 1994; 343: 133-135.

28. Baraldi E, Azzolin NM, Dario C, et al. Effects of atmospheric nitric oxide on measurements of exhaled NO in asthmatic children. Pediatr Pulmonol 1998; 26: 30-34.

29. Therminarias A, Flore P, Favre-Juvin A, Oddou M-F, Delaire M, Grimbert F. Air contamination with nitric oxide: effect on exhaled nitric oxide response. $\mathrm{Am}$ J Respir Crit Care Med 1998; 157: 791-795.

30. Dötsch J, Demirakca S, Terbrack HG, Hüls G, Rascher W, Kühl PG. Airway nitric oxide in asthmatic children and patients with cystic fibrosis. Eur Respir J 1996; 9: 2537-2540.

31. Deykin A, Halpern O, Massaro AF, Drazen JM, Israel E. Expired nitric oxide after bronchoprovocation and repeated spirometry in patients with asthma. Am J Respir Crit Care Med 1998; 157: 769-775.

32. Corradi M, Pelizzoni A, Majori M, Cuomo A, de Munari E, Pesci A. Influence of atmospheric nitric oxide concentration on the measurement of nitric oxide in exhaled air. Thorax 1998; 53: 673-676.

33. Lundberg JON, Farkas-Szallasi T, Weitzberg E, et al. High nitric oxide production in human paranasal sinuses. Nature Med 1995; 4: 370-373.

34. Franklin PJ, Taplin R, Stick SM. A community study of exhaled nitric oxide in healthy children. Am J Respir Crit Care Med 1999; 159: 69-73.

35. Rutgers SR, Meijer RJ, Kerstjens HAM, van der Mark TW, Koëter GH, Postma DS. Nitric Oxide measured with single-breath and tidal breathing methods in asthma and COPD. Eur Respir J 1998; 12: $816-829$.

36. Chambers DC, Tunnicliffe WS, Ayres JG. Acute inhalation of cigarette smoke increases lower respiratory tract nitric oxide concentrations. Thorax 1998; 53 : 677-679.

37. Persson MG, Zetterstrom O, Agrenious V, Ihre E, Gustafsson LE. Single-breath nitric oxide measurements in asthmatic patients and smokers. Lancet 1994; 343: 146-147.

38. Kharitonov SA, Chung KF, Evans DJ, O'Conner BJ, Barnes PJ. Increased exhaled nitric oxide in asthma mainly derived from the lower respiratory tract. $A m$ J Respir Crit Care Med 1996; 153: 1510-1514.

39. Sharma VS, Taylor TG, Gardiner R. Reaction of nitric oxide with haem proteins and model compounds of haemoglobin. Biochem 1987; 26: 3837-3843. 